\title{
Older adults and mobile technology: Factors that enhance and inhibit utilization in the context of behavioral health
}

\author{
Alexis Kuerbis $^{1 *}$, Adina Mulliken ${ }^{2}$, Frederick Muench ${ }^{3}$, Alison A. Moore ${ }^{4}$ and Daniel Gardner ${ }^{1}$ \\ ${ }^{1}$ Silberman School of Social Work, Hunter College at the City University of New York, 2180 Third Avenue, New York, NY 10035, USA \\ ${ }^{2}$ Social Work and Public Health Library, Hunter College at the City University of New York, 2180 Third Avenue, New York, NY 10035, USA \\ ${ }^{3}$ Director of Digital Health Interventions, Feinstein Institute for Medical Research, Department of Psychiatry, Northwell Health, 1010 Northern Blvd., Ste. 311 , \\ Great Neck, NY 11201, USA \\ ${ }^{4}$ Medicine and Psychiatry, David Geffen School of Medicine at UCLA, Division of Geriatric Medicine, Los Angeles, CA 90095, USA
}

\begin{abstract}
While numbers and proportions of older adults with behavioral health issues are expected to substantially increase, there is also a widening gap in available services for older adults. Mobile health interventions (mhealth) are a way to address existing barriers to treatment, provide frontline assessment and increase access to services for older adults. Due to perpetuated stereotypes, many assume that older adults do not utilize mobile technology nor will they accept a mHealth intervention. The purpose of this paper is to synthesize contemporary literature from information technology and healthcare regarding: (1) current mobile technology utilization by older adults, particularly in regards to health; (2) factors affecting older adult motivation to engage with mobile technology; and (3) older adult preferences for interacting with mobile technology. Findings reveal that significant proportions of older adults: already utilize mobile technology; are willing to engage in existing mobile interventions for health reasons; and have positive attitudes overall towards mobile technology. Finally, recommendations for optimizing mobile interventions to better suit older adults with behavioral health problems are reviewed.
\end{abstract}

Baby Boomers began to turn 65 in 2011 and comprise $30 \%$ of the US population [1]. The number of adults 65 and older is projected to increase from 40.3 million to 72.1 million between 2010 and 2030 [2]. An estimated $10.2 \%$ of these adults suffer from mental health and substance use disorders, which comprise what is termed behavioral health. An estimated $2 \%$ have two or more of these conditions. Since both numbers and proportions are expected to increase [3], there is an urgent call for efficient and effective assessment, prevention, and intervention related to behavioral health for older adults [2,4]. This call is coupled with new incentives and funding provided by the Affordable Health Care Act to expand prevention services at the individual and population levels $[5,6]$. Thus, the demand for brief and/or front line behavioral health assessment and intervention among older adults is at an all-time high.

\section{Opportunity for mHealth among older adults}

One way to provide such services for older adults is to use mobile technology, referred to as mobile health (mHealth). mHealth is defined as "handheld [or wearable] transmitting device[s] with multifunctional capabilities used to store, transmit and receive health information" [7]. Devices, such as cellphones, smartphones, tablets, or wearable sensors (e.g., Fitbit), can collect health related data actively or passively; communicate with healthcare providers; and potentially provide real time feedback or interventions to users.

mHealth offers a number of advantages to both older adults and the healthcare system. By providing access to behavioral health information for decision making, behavior change, and monitoring of health conditions, mHealth can enhance the lives of older adults to live independently longer, thus supporting aging in place $[8,9]$. mHealth can also address the unique barriers to services older adults may experience, such as difficulty with cost, severe stigma related to mental health conditions and substance use, and problems with transportation [10]. Because mHealth can be a low cost, low burden way to engage older adults in health care services, it also provides an opportunity to alleviate the increasing burden on the healthcare system, particularly primary care [11].

mHealth interventions that address behavioral health within the general population already exist via short messaging service (SMS) or text messaging, web-based interventions, and/or mobile phone applications [12-17]. While research in this area is still in the relatively early stages [18], many studies demonstrate feasibility and initial effectiveness across a variety of populations and health problems $[13,14,19,20]$. Importantly, while these studies generally exclude adults 65 and older, no study has yet reported significant age differences in responses to the interventions $[13,14]$.

mHealth interventions currently exist for older adults in medical fields other than behavioral health [21,22]. Among older adults, mHealth is rapidly expanding to address medical conditions, such as

Correspondence to: Alexis Kuerbis, LCSW, Ph.D., Assistant Professor, Silberman School of Social Work, Hunter College at the City University of New York, 2180 Third Avenue, New York, NY 10035, USA; Tel: 917-301-7903; E-mail: ak1465@ hunter.cuny.edu

Key words: older adults, mHealth, technology, mental health, substance use disorder

Received: April 04, 2017; Accepted: April 27, 2017; Published: April 29, 2017 
cardiovascular disease [23], pain management [7], fall detection [24], medication adherence [25], and remote home-based health monitoring [26]; however, mHealth remains in its nascent stages related to behavioral health and older adults. This difference may be due to an overall lag in technology use by the behavioral health field compared to other fields of medicine.

\section{Potential barriers to application of mHealth to older adults}

Another possible explanation as to why older adults remain excluded from mHealth targeting behavioral health is a lack of understanding the factors that affect older adult engagement in technology. Across the globe, stereotypes persist that older adults are afraid, unwilling, and unable to use technology, including computers, email, the internet, and mobile phones [27-32] - causing a "digital divide" [33]. Many of these stereotypes are perpetuated by older adults, who may believe themselves incapable of learning to use technology [34]. Interestingly, within healthcare, older adults are often required to engage with technology, ranging in complexity from wireless heart monitors to feeding tubes $[21,32,35]$, with little thought to their comfort with or ability to utilize it.

Empirical evidence suggests that older adults are a heterogeneous group with a range in comfort and expertise with technology [9]. Utilization of technology is also highly influenced by generational cohort. While the above described perceptions may apply to previous generations or subgroups of older adults, generally, Baby Boomers significantly differ from generations before them in their exposure to a variety of technologies $[33,36]$.

Older adults also experience actual barriers to engaging with technology. Disabilities occurring with the onset of aging or resulting from disease may inhibit an older adult's interaction with technology. Even mild visual impairment can hinder the older adult's ability to effectively navigate a webpage or mobile application on a smartphone [37]. Individuals with more severe disabilities may be discouraged from using mobile technologies altogether.

In order to provide an optimal context in which mHealth interventions focused on behavioral health are developed for older adults, it is important to understand the potential barriers to and facilitators of, as well as preferences for, engagement with technology among this population. For this paper, we define older adults to be adults 50 and older, as some of the cognitive and physical changes that begin at that age can cause interference with technology engagement [33]. Thus, we include Baby Boomers, who in 2016 were aged 52 to 70. The purpose of this paper is to synthesize contemporary literature from information technology and healthcare regarding: (1) current mobile technology utilization by older adults, particularly in regards to health; (2) factors affecting older adult motivation to engage with mobile technology; and (3) older adult preferences for interacting with mobile technology. Key words were used in various combinations to search for relevant research articles and reports that might inform the above defined aims. They included: older adult, age, aging, technology, mobile technology, mHealth, mobile interventions, computer, social factors, technology utilization, stigma, SMS messaging, text messaging, tablet, cell-phone, mobile phone, internet, web-based, and online. Over 150 articles and reports were found. Those that did not report on adults 50 and older were excluded, reducing the final number to 96 . Findings are synthesized below into themes. Finally, based on the synthesis, recommendations for optimizing mobile interventions to better suit older adults with behavioral health problems will be discussed.

\section{Older adult utilization of technology}

Over the last decade, there is a substantial increase in selfinitiated use of technologies related to mHealth by older adults [33]. Contemporary rates of utilization of technologies most used by mHealth will be reviewed, including the internet, email, cellphones and smartphones, text messaging and tablets. Table 1 provides basic utilization rates of each type of technology by age group.

\section{Internet and email}

High rates of internet use are reported among adults from about age 50 years old until around age 70, when it drops off (Table 1). Whether this is due to age or a generational effect is unclear, as there is evidence that older adults who use technology start to disengage after a certain age [36]. Regardless, older adults are the fastest growing group of online users $[38,39]$, and Baby Boomers utilize the internet at rates on par with generations after them [40]. Even among adults 71 and older, email is the second most preferred form of communicating after calls [41].

Older adults tend to use the internet for health purposes [4244]. A national survey revealed that, among Baby Boomers, about half go online for some health related purpose [40], such as ordering prescriptions or obtaining health information.

Several studies recently investigated the feasibility and efficacy of utilizing email and web-based platforms with older adults to facilitate communication with providers and intervene with health behaviors. Lam and colleagues [45] investigated consumer participation with an online platform that facilitated physician-patient communication, akin to a personal email account where the physician is the only recipient. Older adults $(\mathrm{N}=145)$, mean age 74.5 years, and a younger cohort, mean age 48.8 years, self-selected into groups of users and non-users of the platform. Results demonstrated the older adult group preferred emails over telephone calls as the primary means of communication, and $71.3 \%$ were satisfied with the system. It may be that utilizing email increases access to the health care provider.

Internet-based interventions for older adults are in development and pilot phases. For example, in a pilot study of 25 adults 55 years old and older, investigators tested the initial efficacy and acceptability of an interactive, web-based intervention for over-active bladders [46] that included online learning modules (featuring diagrams, videos, and case-examples) and discussion boards to ask experts questions. Participants reported high satisfaction with the program, with $88 \%$ reporting it was easy to use. The pre-to-post tests revealed large effect sizes for all outcomes, including reduced symptoms and increased selfefficacy and quality of life.

Another study of 20 adults 60 and older with elevated depressive symptoms [47] tested the feasibility of an internet-based cognitive behavioral therapy for depression. In addition to five online education modules, participants were asked to do homework, participate in discussion forums, and have weekly contact with a clinical psychologist via email and phone (totaling about an hour for each participant across eight weeks). Sixteen participants out of 20 completed the online modules over eight weeks. Pre-to-post tests revealed large effect sizes for overall health and decreased depressive symptoms.

Finally, a study of the individuals who visited alcoholscreening. org during 2013 [48] reported that over 18,000 individuals between 50 and 64 years old and 3,485 individuals aged 65 to 80 years old visited the website for screening of alcohol use. Over $80 \%$ of the oldest group reported exceeding the recommended daily limit of drinking. 


\section{Cellular phones and smartphones}

Table 1 shows a majority of older adults owned a cell phone in 2013 [39]. Among adults 65 and older, cell phones are most often used for the calling/voice feature [49-51], and depending on the sample, calendars, emailing and text messaging are the next most commonly used features [50,52-54]. Individuals 50 and older use their smartphones primarily for text-messaging, internet access, phone/voice features, and email [44]. Across age groups in the US, the most often cited reason for accessing the web on mobile phones (62\%) is for health information.

Already smartphones have been utilized for studies on pain management and for collecting data about older adults in a real world setting, often referred to as daily diary assessment (DDA) [7]. A systematic review of studies on pain that utilized electronic DDA implemented via smartphones, personal digital devices, and tablets reported: (a) high compliance rates overall among subjects aged 18 to 83 [55] and (b) rates of compliance significantly increased as the subject's age increased. In a recent study that implemented smartphone-based DDA with 48 problem drinkers aged 50 to 73 demonstrated that $100 \%$ had their own smartphones, and compliance rates with the DDA were higher among older adults than the younger cohort ( $78 \%$ vs. $72 \%$ over the course of 49 days) [56].

\section{Short message service (SMS) or text messaging}

Nearly all mobile phones have SMS capability. In 2011, adults 55 and older who had a phone with text messaging capabilities sent or received a median of two text messages a day [57]. Utilization of text messaging as an adjunct to primary care for older adults is growing, and private companies are selling text messaging services to health care providers serving older adults [21]. While adults over 50 are included in many samples, few studies focus on adults over 50 as a target population or report findings by age group. When they do, older adult willingness to receive appointment or medication reminders by text message does not differ from younger adults [58].

Five published studies have explicitly studied text messaging as an adjunct to care among older adults. In a study of 580 adults with a mean age just under 65, 290 participants (50\%) opted into a text messaging service to enhance medication adherence for diabetes, cholesterol, and/or heart disease [25]. Participants who opted for text message reminders were significantly more adherent to their oral medications than the matched controls who did not opt for the service.

A randomized controlled trial of 90 individuals with coronary heart disease tested the feasibility and initial efficacy of a text messaging intervention for medication education and adherence [59]. Participants

Table 1. Rates of utilization of technology by age group and technology type

\begin{tabular}{|c|c|c|c|}
\hline \multirow{2}{*}{ Type of Technology } & \multicolumn{2}{|c|}{ Age Group } & Study \\
\hline Internet & $87 \%$ in 2013 & $\begin{array}{c}\text { 65+ } \\
59 \% \text { in } 2013 \\
65-69 \text { year olds: } 74 \% \\
70+\text { year olds: } 47 \%\end{array}$ & {$[39]$} \\
\hline Email & $91 \%$ in 2014 & $87 \%$ in 2014 & {$[44]$} \\
\hline Cellular phones & $90 \%$ owned in 2015 & $78 \%$ owned in 2015 & {$[117]$} \\
\hline Smartphones & $58 \%$ owned in 2015 & $30 \%$ owned in 2015 & {$[117]$} \\
\hline SMS/Text Messaging & $92 \%$ in 2015 & $92 \%$ in 2015 & {$[117]$} \\
\hline Tablets & $37 \%$ in 2015 & $32 \%$ in 2015 & {$[117]$} \\
\hline E-Readers & $19 \%$ in 2015 & $19 \%$ in 2015 & {$[117]$} \\
\hline
\end{tabular}

Note: Data from national surveys from the Pew Research Center in years 2013, 2014 and 2015.

a Includes Baby Boomers, who were born between 1946 and 1964, and in 2016 were between 52 and 70 years old. were aged 35 to 83 years old, with a mean age of 59 . The intervention demonstrated significantly higher rates of medication adherence than the control group. Interestingly, adherence to statins, a medication often taken in the evening, was not affected by text messaging. Investigators theorize that timing of medication administration moderated the efficacy of the intervention because individuals may not be looking at their mobile phones as often later in the day. Participants reported high satisfaction with receiving health care related text messages and that receiving such messages made them feel someone cared. This feeling someone cared is consistent with other text messaging interventions across age groups, including patients of methadone maintenance programs [60].

A third study implemented a four week text messaging intervention for medication adherence among urban African Americans with diabetes, with a subsample of older adults [61]. This feasibility study recruited a sample $(\mathrm{N}=18)$, with mean age of 55 , that included nine adults aged 55 to 72 years old. Results were not reported by age group but demonstrated that missed medication decreased significantly for the whole sample. Participants reported the intervention was easy to use and helpful in monitoring their self-care.

Using single case design, one study explored the experience of two subjects, one aged 82 and one aged 60, taking part in a new interactive monitoring and feedback intervention for diabetes [62]. This intervention combined ambient, device level (e.g., wireless remote scale, Bluetooth connected blood glucose monitors) and passive (e.g., a wearable device that monitored steps, sleeping, etc.) sensing. Feedback about calorie intake, blood glucose levels, and activity level was provided via text messages. Both subjects demonstrated improvement in blood glucose levels, activity, and weight over 40 days.

Finally, a recent study examined the impact of a text messaging intervention on increasing exercise among adults 55 to 70 years old [63]. All participants $(\mathrm{N}=43)$ received an exercise booklet, and those randomized to the SMS condition received five text messages each week, for 12 weeks. Those in the SMS condition demonstrated significantly greater amounts of exercise than the non-SMS condition; however, once the text messages stopped, there were no longer significant differences between groups.

\section{Tablets}

Rates of tablet ownership (Table 1) among older adults lag behind younger adults who demonstrate rates of ownership of over $50 \%$. In two case studies of 23 older adults learning to use tablets, findings demonstrate older adults preferred tablets to computers, citing their greater ease of use [34], even when they anticipated it would be difficult to learn. The size of tablets may make them more appealing to learn than computers. An experimental study of 24 novice technology users aged 50 to 70 demonstrated they were able to achieve tasks more quickly on a touch screen than using a mouse and keyboard or voice assisted navigation [64]. A study of 10 adults aged 67 to 87 compared speed and accuracy of searching and navigating health webpages while using either tablet or a computer [65]. While participants navigated the pages more slowly using a tablet, overall ease of use of the webpage itself, as subjectively reported by the users, presented the primary obstacle.

Tablets and personal digital assistants have been used successfully in both educating and monitoring older adult health. An interactive personal education program (PEP) on medication interactions was implemented via a touch screen laptop (mimicking a tablet) and tested for efficacy over and above an information booklet for 85 adults 60 and older [66]. The PEP group had significantly higher rates of self-efficacy 
and knowledge about drug interactions and lower rates of adverse self-medication behaviors compared to the information booklet only and control groups. Another study [67] tested a PEP on medication interactions and adherence delivered via a tablet on 33 adults, mean age of 80 . Older adults rated the PEP as useable, useful, and highly satisfying.

\section{Factors influencing motivation to use and engage with technology}

Utilizing Chen and Chan's (2013) [52] model, we discuss three types of factors influencing older adults' access and motivation to use technology: personal, technical, and environmental.

\section{Personal factors}

Functional capacity. Functional capacity refers to age-related changes in physical and mental capabilities that may affect engagement with mHealth and technology [33]. For example, visual and motor limitations may cause an older adult to perform a technology-based task more slowly than someone without such limitations [37]. Type and severity of disability varies across individuals. Importantly, not all older adults experience increasing disability as they age; however, certain common aspects of aging can affect one's ability to engage with mHealth technology.

Visual impairments make engaging in mHealth problematic. Acuity, color perception, and contrast sensitivity all diminish with age [33], impeding an older adults' ability to read webpages, mobile apps and mobile phone screens that use complex fonts, too many visual elements, or colors that are not sharply contrasted. In addition, older adults have limited eye movement that causes them to inadvertently ignore the periphery on websites and perform slower on web-based tasks [68].

Hearing loss is also common in aging. As adults age, they have increasing trouble hearing higher pitched sounds, deciphering fast speech, and understanding speech over a noisy background $[69,70]$. This may hinder older adults' ability to understand synthetic voices. While hearing loss is not typically an impediment to technology engagement, due to the dominant use of visual information, an increasing reliance on video, gifs with sound, music and other multimedia may cause increasing barriers to technology engagement.

Deterioration of fine motor coordination or the presence of tremors (such as from medication side effects or certain diseases) can also impair older adults' ability to effectively utilize mobile technologies $[34,69]$. For those with this type of limitation, touch screens with small buttons or buttons that are too close together yield high error rates $[34,71]$. Other conditions that limit dexterity may render using a mouse or a key pad impossible (Damodaran et al., 2014), but manifestations of such diseases are heterogeneous and do not universally hinder older adults' abilities [58].

Cognitive changes may also impact an older adult's facility to engage with mHealth. For example, spatial visualization, the ability to mentally manipulate two and three dimensional objects, lessens with age [72]. This ability allows an individual to mentally imagine the hierarchical structure of a webpage. Without this ability, navigating complicated webpages becomes very difficult. Fluid intelligence--skills and abilities relating to short-term or working memory, problemsolving in new situations, inhibitory control and speed of processingalso declines with age $[73,74]$. This decline can cause difficulty with filtering extraneous information (or animated software components) and learning how to utilize technology to occur at a slower pace than younger adults $[33,73,75]$. Working memory may become easily overloaded, interfering with task performance $[73,76]$.

Cognitive decline is widely variable among older adults [77], and not all older adults will experience the difficulties described above. Older adults may also hold some advantages over their younger counterparts in relation to technology, due to larger, more expansive vocabularies [72,73]. For example, in a study of 45 adults 60 years old and older compared to 72 young and middle-aged adults, older adults were found to perform as well as the younger cohorts and, in some cases, better on certain web-based tasks, such as search and retrieval [78], which rely on vocabulary.

Mental and physical health also influence an older adult's motivation to engage in technology. Using a sample of Medicare beneficiaries 65 years old and older $(\mathrm{N}=6,680)$, Choi and DiNitto et al. [79] found that having more chronic medical conditions increased the odds of using the internet for health-related tasks by $15 \%$ and that depression and anxiety were negatively related to internet use. While anxiety symptoms reduced internet use by $26 \%$, they increased use of emailing and text messaging (measured in aggregate) by $75 \%$. Another study of Medicare beneficiaries found that use of information and communications technology among adults 65 years old and older was positively correlated with self-rated health and absence of disease [80].

Knowledge. Previous experience with or exposure to technology is another factor affecting older adult engagement with technology. Many adults now 50 and older utilized computers as a part of their employment [42]. These individuals demonstrate a level of comfort with new technology, while others without such experience do not $[52,81,82]$. For those without previous experience, utilizing new technologies may be foreign and daunting $[52,83]$. A lack of knowledge about: technology jargon, why automatic software updates occur, and skills to solve problems as they occur (ranging from "blue screen" to viruses) contribute to older adults feeling frustrated and out of control [36,52].

Dispositional characteristics. Older adults who experience disability due to aging are less likely to view themselves as disabled, and thus may be less likely to seek, be exposed to or take advantage of adaptive technologies available $[84,85]$. In addition, shame related to using adaptive or non-standard versions of technologies, particularly those that are visible, can lead them to be rejected by older adults [33]. For some, utilizing such devices is an embarrassing admission of dependence [35]. Interestingly, older adults may be more likely to engage with technology, including electronic health records, when it helps to treat or address stigmatized illness, such as depression [86] and HIV [87].

Older adults may also avoid technology when they have little selfconfidence about learning something new $[9,52,88]$. Two qualitative studies $[52,89]$ using focus groups and individual interviews of 63 older adults revealed that participants perceived themselves as too old to learn certain technologies [52]. Some older adults experience anxieties and fears that they will make fatal mistakes while using technology, such as inadvertently deleting a file or breaking the device, which facilitates a self-perception as being incapable of utilizing technology $[34,70,90]$. While this low technical confidence does not to hinder effectiveness or efficiency of using technology in the general population, one study directly compared the impact of technical confidence of older adults (ages 50-69) and young adults (18-27) on technology usage and found older adults' low technical confidence hindered both efficiency and effectiveness [37]. 
Attitudes towards and motivations to use technology. A majority of older adults report positive attitudes towards technology, including the internet, email, text messaging and smartphones [9,43,67,91]. A large ethnographic study in Ireland demonstrated that older adults adapted to waves of new technologies across their lifetimes, suggesting a higher level of acceptance and readiness than previously assumed [92]. Older adults demonstrate positive attitudes towards technology, as it is "a conduit to youthfulness" [67], helping them to communicate with younger generations. Furthermore, in a national survey, adults over 50 were more likely to evaluate their smartphone as liberating compared to younger adults who viewed it as a leash [44]. Fifty percent of older adults viewed their smartphones as making them more productive.

The American Association for Retired Persons [93] surveyed its members (aged 50 and older) and found they are aware technology can help them remain independent, gather information, and promote and maintain their personal health and wellness. In addition, $75 \%$ of respondents were willing to use technology to allow remote monitoring of health conditions. Another study of 113 community dwelling older adults found that $35 \%-38 \%$ were interested in technology for monitoring and gathering information about health behaviors [9].

Two of the most consistent predictors of technology disengagement across studies are perceived usefulness of and lack of interest in technology $[33,94]$. When there are no clear benefits to its utilization, such as maintaining autonomy and independence, the older adult is far more likely to disengage from or avoid technology $[9,37,47,50,52,75,82,91]$. Lack of interest may be due in part to: a perception that it does not fulfill a salient need [52]; an indirect reflection of other personal factors, such as anxiety, fear, or lack of self-efficacy [90]; or simply that time is better spent doing something else [52]. Some older adults report reaching a "technological plateau", at which there is no perceived utility in adapting again to new technologies [92].

Physical safety. Safety is a primary motivator for using mobile phones $[30,82,92,95]$. Many older adults rely on their mobile phones for emergencies, both inside and outside of the home. They also have concerns about technology's effect on one's health. Several studies have documented that older adults fear both being addicted to the phone and technology's impact on society, as they witness younger generations glued to their devices $[52,95,96]$. Older adults also express concerns about health issues that may arise directly from mobile phone usage [54], such as effects of radiation [95], eye strain, headaches and pain in muscles and joints [52].

Privacy and confidentiality. For any technology user, maintaining privacy and confidentiality is essential [82]. While some older adults avoid using technology for security reasons [9,52], doing so to prevent breach of confidentiality was surprisingly absent from the literature. Instead, older adults were concerned about the effects of pop-ups, viruses, and scams that might cause other kinds of damage [36].

Some older adults describe technology as intrusive [82]. In a qualitative study on Australian older mobile phone users [30], participants reported that the constant ability to be contacted was a nuisance, as was the expectation of an immediate response. Participants reported turning their phones off to maintain a sense of privacy. This is consistent with findings that older adults tend to have their phones turned off towards the end of the day [58,59].

\section{Technical factors}

Device related design. Device related features may provide unique obstacles for older adults. For example, buttons on cellular phones may not be clearly or explicitly labeled, either due to font size or potentially cryptic symbols on the buttons [34,95]. Touch screens are often incorrectly calibrated to an older adults' level of motor function and can be too sensitive to the touch.

Website or application design. Design of operating systems, websites, and device applications can create additional obstacles. Tools, such as a click-and-drag operation or "predictive text", where words are input into a text message, search field, or email on a smartphone with just the typing of a few letters, can impede an older adult's ability to easily utilize these features $[58,70,95]$. Due to potential decline of fluid intelligence, websites or applications that rely heavily on an individual's spatial visualization create excessive mental burden $[33,52,73]$. Over reliance on either symbols or text alone can cause utilization barriers for older adults (Center for Persons with Disabilities, 2015; Hanson, 2011) [33,97]. Websites or applications that are dynamic-that continually change images or headlines-are also not suited to older adults who are more prone to "change blindness" [33]. While all may find online forms with insufficient labels, ambiguous links, links or buttons that are too small or too close to one another, or providing information in a new window frustrating, these characteristics are particularly disorienting for older adults struggling with cognitive and motor coordination changes $[69,70]$.

An absence of feedback to the user is also particularly problematic for older adults $[34,82,95]$. Feedback refers to when a website or application provides some indication that a button has been pushed or a task has been completed. Feedback fosters self-efficacy, which facilitates all learning. Without such feedback, the older user can become disoriented [95], wondering if a task is complete or how to undo the error. Large, complicated websites, such as Medicare.gov, that have an absence of feedback impose high cognitive load on older adults [98].

Often a critical component of interfacing with mobile devices, gesturing and tapping may be barriers to older adult technology engagement. Directional gesturing (e.g., using fine motor coordination to adjust a slide ruler) is more difficult for motor-impaired individuals [71], while "tapping" (e.g., one touch) and "crossing" (e.g., "slide to open") are more easily accomplished. In addition, requiring multitapping for navigation is also problematic for older adults compared to younger cohorts [82].

Complexity/usability. Technology is embraced and adopted by older adults when it is perceived as easy to use $[9,30,99]$ or specifically designed for them. For this reason, many older adults choose models of technology that are the simplest, rather than the most contemporary [50]. Importantly, effectively learning how to use a device will shape attitudes about usability. A study on 16 older adult users of personal digital assistants found that once they were able to complete a task successfully, they were more likely to rate the device as easy to use [37].

\section{Environmental factors}

Financial costs. Cost of a device or its services greatly impact older adults' access to technology [30,40,52,75,76,79,80,95,]. Older adults living on fixed incomes may not be able to afford to purchase any device, let alone the latest versions. Even "hand me ups" from adult children or public programs are often slower or less sophisticated [33]. While programs exist to provide access to cell phones, such as Temporary Assistance for Needy Families, these phones are often shared within families, inhibiting access to a particular individual at a particular time for mhealth interventions [60].

Across age groups in 2014, nearly half (48\%) of individuals who owned smartphones in the U.S. terminated their service 
due to its burdensome cost [44]. Individuals from impoverished socioeconomic classes will be hardest hit by these burdens $[40,79,80]$ disproportionately affecting certain racial and ethnic groups. AfricanAmericans and Latinos are far more likely to be reliant on their smartphones for internet access and to report no access to broad band services. Termination of smartphone services may prohibit mHealth interventions for certain groups.

Social influences. Social factors either facilitate or hinder an older adults' motivation to use technology. Several studies report that older adults are motivated to use technology to "keep up with society" [52]. In a qualitative study of 44 adults with a mean age of 67 , respondents reported that engaging with technology was a "basic skill", akin to literacy [36].

Older adults also view technology as a way of avoiding social isolation [50]. For example, a homebound, disabled person can use technology to obtain information via the internet [36]. Older adults find modern technology crucial for connecting with younger generations $[41,50,96,100,101]$. While connection is key, some older adults report text messaging was also helpful in keeping family out of the house and "out of their business" [92].

Several studies found older adults fear technology will replace faceto-face social interaction $[35,52,95]$ and thus only care to use it as a compliment to existing points of contact. In a cross-sectional online survey [102] in which $20 \%$ of respondents $(\mathrm{N}=1,132)$ were older than 60 years old, investigators found older adults were less likely to want to use mHealth or other technologies as a substitution for or as a compliment to a doctor's visit than their younger counterparts.

Many older adults avoid asking their family or friends for help because they do not want to reveal their lack of knowledge $[35,92]$. Power differentials between children and parents shift as a result of asking for help. This could be problematic in certain cultures where hierarchy between children and parents is life-long $[52,82]$.

Additional cultural factors may have important implications among older adults. Haddad and colleagues (2014) [103] found preferential differences on webpage presentations between Caucasian and East Asian older adults $(\mathrm{N}=36)$. East Asians preferred a rich interface that was complimented by learning support and security, while the Caucasians preferred a more minimal interface. These differences were hypothesized to relate to whether a culture was an individualistic or collectivistic society.

Several studies also report many older adults do not want others to know that they are dependent on assistive devices of any kind [27,35]. Fifty older adults asked about preferences related to memory aids reported being embarrassed about having others know they needed such aid [35,104]. Older adults also express concern about feeling overly monitored and fearing their behaviors would be judged or stigmatized [35].

Learning to use technology. The context in which an older adult learns to use technology has an important impact on the older adult's attitude towards, self-efficacy in using, and ultimate level of engagement with technology. Older adults appear to rely primarily on three forms of learning about technology: trial and error, step-by-step instruction manuals, and in person instruction [34]. If given a supportive environment, generally older adults are able perform basic maneuvers after only a few minutes $[30,34,105]$, even if they require more time to master the same tasks as younger adults [33]. While older adults rely on step-by-step instruction manuals more than younger adults $[36,82]$, current technology trainings, including manuals, are often not tailored to older adult learning capabilities [99].

Many older adults prefer to have face-to-face tutelage to resolve a technological problem $[36,106]$. Older adults have expressed need for locally available, in-person, expert, technical advice [106] and training $[36,50]$. Older adults who receive training perform better on technical tasks-with greater accuracy and speed [107]. Importantly, trainers working with older adults must not hold negative stereotypes towards the individuals they are helping. Empirical studies show older adults' computer-related anxiety increases in the context of having tutors who maintain negative stereotypes towards them [105], thus decreasing their technology self-efficacy. Older adults report that support and encouragement from friends, families, and tutors are key to ongoing engagement with technology [36].

\section{Recommendations for increasing accessibility of mHealth for older adults}

While all potential users are interested in technology that is "useful, functional, useworthy, and meaningful" [27], the recommendations made below are particularly crucial to successfully engage older adults as a heterogeneous group of mHealth users. Table 2 provides a list of primary recommendations for mhealth with older adults and behavioral health based on this review.

\section{Providing a context in which older adults learn and adopt technology}

The learning environment (Table 2) must have several components for optimal engagement of older adults, including ample time, tutors who communicate belief in new older adult technology user to learn to use the technology, and multifaceted training and support $[34,36]$. Ideally, training is available at the local level and offered in person, along with manuals that provide step-by-step instruction in lay language.

Any technology serving older adults must have a clear purpose towards advancing the older adult's quality of life, health, safety, wellbeing, and independence $[35,36,50]$. Designing for the whole person inherently encourages ongoing technology utilization [27]. Providers of mHealth interventions for older adults need to introduce their potential intervention or product with this purpose in mind [35]. Involving older adults from the inception of the design will ensure this purpose is important to the older adult user [36].

Older adults wish to feel accommodated as welcome customers $[27,108]$. This can be achieved by tailoring interventions to individual preferences. For example, a mHealth intervention might be offered via multiple modalities, such as text message, email or calendar reminder. Like the general population [109], tailoring to the unique needs of each older adult maximizes engagement and efficacy [35].

\section{Universal accessibility}

While there is no single set of standards for older adults' universal access to mobile technology, several sets of standards exist for making applications and websites accessible for people who experience the age-related changes described above. Although not all changes are considered "disabilities," some sets of guidelines are proposed to address accessibility for both older adults and those with disabilities. A widely accepted set of technical standards for people with disabilities is the Web Content Accessibility Guidelines 2.0 (WCAG 2.0) [110,111]. WCAG 2.0 includes standards that enable a website to function for people with significant physical, visual or other disabilities [112], and 
Table 2. Summary of Main Recommendations for Providing Optimal mHealth Interventions for Older Adults

\begin{tabular}{|c|c|}
\hline Feature & Description \\
\hline $\begin{array}{l}\text { Supportive training and } \\
\text { learning environment }\end{array}$ & $\begin{array}{l}\text { 1. Older adults must be given time to examine, explore, } \\
\text { and experiment with a device at their own pace [34,37] } \\
\text { 2. Tutors, whether professionals or loved ones, should } \\
\text { treat the new older adult technology user in a positive } \\
\text { manner, communicating a belief that the older adult will } \\
\text { be able to learn to use the technology [105]. } \\
\text { 3. Providers should be sure to provide training that does } \\
\text { not rely on the older adult's family members to assure } \\
\text { their utmost privacy and to protect family hierarchy [52]. } \\
\text { 3. Training and learning support must be multifaceted } \\
\text { [36], ideally offered in-person and available at the local } \\
\text { level. } \\
\text { 4. Training manuals should be written in lay language, } \\
\text { providing simple step-by-step instruction, so that an older } \\
\text { adult may easily refer back to it [36]. }\end{array}$ \\
\hline Affordance & $\begin{array}{l}\text { Affordance is when an action that needs to be taken by a } \\
\text { user presents itself intuitively. There is little question of } \\
\text { what needs to be done to complete a task [34]. }\end{array}$ \\
\hline Feedback & $\begin{array}{l}\text { Feedback is information provided to the user that they } \\
\text { have completed a task successfully. Feedback ranges from } \\
\text { a vibration or sound when a button has been pressed to a } \\
\text { notification letting the user know a form is complete [34]. }\end{array}$ \\
\hline Error recovery & $\begin{array}{l}\text { Error recovery refers to, when a mistake is made, the } \\
\text { ability of the interface to easily allow and, in some cases, } \\
\text { specifically direct users how to correct it [34]. }\end{array}$ \\
\hline Timing of intervention & $\begin{array}{l}\text { An mHealth intervention may be best timed for the } \\
\text { morning or afternoon, rather than late in the day due to the } \\
\text { potential for phones to be turned off at that time [25]. }\end{array}$ \\
\hline Universal access & $\begin{array}{l}\text { Specific design features should consider the physical and } \\
\text { cognitive changes that commonly occur as a part of aging. } \\
\text { See Table } 3 \text { for some examples. }\end{array}$ \\
\hline Transparency & $\begin{array}{l}\text { The device and its software must be "transparent" [34], } \\
\text { meaning that the perceived learning difficulty is low. }\end{array}$ \\
\hline Invisibility & $\begin{array}{l}\text { Any device or intervention must be "invisible" or } \\
\text { unobtrusively integrated into the older adults' life so as to } \\
\text { protect privacy and decrease shame [35]. }\end{array}$ \\
\hline Clear Purpose & $\begin{array}{l}\text { Any technology serving older adults must have a clear } \\
\text { purpose towards advancing the older adult's quality } \\
\text { of life, health, safety, well-being, and independence } \\
{[35,36,50] \text {. }}\end{array}$ \\
\hline
\end{tabular}

includes recommendations of adaptations that also serve older adults [110]. A complete discussion of universal accessibility is beyond the scope of this review, but an abridged list of technical recommendations for device and software design for older adults are presented in Table 3. Furthermore, there are also established techniques to determine whether a website or device interface is accessible by older adults, reviewed elsewhere $[69,98,113,114]$.

\section{Additional design considerations}

For those who avoid technology due to feelings of shame related to having to use such devices, mHealth must be unobtrusive or "invisible" so that the older adult is not forced to reveal themselves as someone who needs help [35]. With the advent of mHealth devices and applications that are universally marketed, such as the Fitbit or an application embedded in a smartphone, issues of visibility may be less and less relevant. Many adaptations for increased accessibility are already coming standard in many mobile devices, such as adjustable font on a smartphone [82].

Service providers are unlikely to develop a one-size-fits-all set of mHealth devices and applications for older adults [36], particularly when evidence suggests that mHealth interventions are most effective when tailored to their particular audience. This is due in part to the heterogeneity of the older adult population. The current health, well-being and experience of aging for an adult aged 55 may differ greatly from one who is 80 years old. Among those older adults who experience increasing disability with age, many may experience more than one (e.g., low vision and hand tremors) and differing intensity of those disabilities-requiring much different levels of accommodation both from the device and the services provided $[33,36,70,96]$. Service providers will need to determine their specific audience for their mHealth interventions, including considering cognitive limitations or preferences that result directly from behavioral health issues [79].

Utilizing mHealth interventions with older adults inherently comes with a series of tradeoffs and decisions that need to be made at the design stage for providers [115]. For example, website and application designs that rely on using vocabulary and language more than spatial ability for navigation $[73,33]$ may put younger users at a disadvantage. Using strategies such as providing both text and graphics may help resolve such dilemmas.

\section{Potential pitfalls of mHealth and considerations for fu- ture use}

There are a number of potential challenges with mHealth interventions. The first major challenge is cost of design and implementation of these interventions-apart from whether or not the older adult user can afford an appropriate device. Currently, there is no system of payment or reimbursement for mHealth services [60]. This is

Table 3. A selected list of examples of specific design features recommended for adapting technology to older adults

\begin{tabular}{|c|c|}
\hline Feature Accommodating Visual Impairments & \\
\hline Larger display & {$[82]$} \\
\hline Large icons, $50 \%$ larger than standard & {$[82,95]$} \\
\hline Font size no smaller than $12 \mathrm{~mm}$ & {$[70,82]$} \\
\hline Buttons no smaller than $12 \mathrm{~mm}$ & {$[70,82]$} \\
\hline Elimination of small web page changes & [71] \\
\hline Elimination of "elaborated text" such as italics or bold & [33] \\
\hline Colors - reds, oranges, and pinks, rather than cool colors & {$[70]$} \\
\hline Negative polarity (light text on dark background) & {$[70]$} \\
\hline \multicolumn{2}{|l|}{ Feature Accommodating Cognitive Impairments } \\
\hline Provision of search reminders when presenting search results & [33] \\
\hline Provision of navigation bars & {$[70]$} \\
\hline Increased use of vocabulary & {$[33,72]$} \\
\hline Place vocabulary/text based navigation menus on the upper and left side & {$[33]$} \\
\hline No flashing or blinking objects & {$[70]$} \\
\hline No pop windows or tasks opening in new windows & {$[70]$} \\
\hline Limited number of menus with limited options - no deep hierarchies & [95] \\
\hline \multicolumn{2}{|l|}{ Feature Accommodating Motor Impairments } \\
\hline Font on touch screens at least $17 \mathrm{~mm}$ & [71] \\
\hline No required directional gesturing & [71] \\
\hline No task requiring click and drag & {$[70]$} \\
\hline Allowing for slower response times from a user & {$[70]$} \\
\hline \multicolumn{2}{|l|}{ Additional Features } \\
\hline A panic button (on mobile phone) & [95] \\
\hline Combination of text and symbols (no reliance on one or the other) & {$[33]$} \\
\hline
\end{tabular}

Note: This is an abridged, limited sample of recommendations for older adults. It is by no means comprehensive. For a full list of recommendations, please consult the $\mathrm{W} 3 \mathrm{C} \mathrm{Web}$ Content Accessibility Guidelines (WCAG) 2.0. In addition, these recommendations may be more complex than they appear here in this table. For example, text size can depend on how the user has configured settings on their device and, when relevant, their browser. WCAG 2.0 Guideline 1.4.4 requires, "except for captions and images of text, text can be resized without assistive technology up to 200 percent without loss of content or functionality" [111]. This provides accessibility to a wider group of older adults than if a designer used a fixed font size, which is not recommended; however, studies, such as those listed above, that recommend a particular font size seem likely to be more useful and understandable to a direct service provider who might want to use such recommendations to help prepare default settings on devices for older adults. 
an extreme barrier to provider implementation of such services, as the design, vetting of accessibility, and initial implementation of a mHealth intervention may be quite costly. This also includes providing adequate training to staff and assess barriers to provider engagement prior to introducing technologies to patients. Monetary incentives for providers to implement and utilize such a service are not entirely clear-some costs may be reduced over the long term, while development costs at the outset are high.

mHealth interventions must be integrated into the healthcare system as a part of a broad set of available services [7,60]. mHealth for older adults will be optimally successful when utilized in conjunction with face-to-face contact with providers [92]. Part of service integration involves capitalizing on the large amount of data collected via mHealth interventions. Providers may be overwhelmed by the amount of data they receive. Without analyzing it and integrating it successfully into platforms, such as an electronic medical record, the real value of the data may be lost. Finally, policies related to participant emergencies must be written. A client who expects a response to reporting an emergency must be able to trust that healthcare providers will follow up if such information is disclosed via a mHealth intervention [60]. This is particularly crucial in behavioral health, which may include participants with high risk for suicidality.

Technical problems, such as programming or communication errors, can also be a major pitfall for mHealth interventions, as they cause stress for both the client and the provider [60]. This may be accentuated for older adults, who may assume they caused the problem, and thus not report the problem to the provider. Outages, for example, can be highly problematic-with loss of data and potentially loss of important connection with clients, undermining the intervention itself.

There is also an absence of any ethical framework to guide emerging technologies for older adults [99]. Considerations related to privacy, autonomy and consent are not well discussed or described $[35,116]$. There is a very real intrusion into the life of the mHealth participant that may be experienced as particularly burdensome to the older adult and may not outweigh the potential benefits of the intervention. In addition, where data is stored, who has access to the data, and what will be done with the data are important aspects to the consenting process that are not often well described to any participant, let alone an older adult who is not accustomed to such intrusion.

\section{Benefits of mHealth for older adults' behavioral health}

mHealth is already being used to assess and intervene with older adults for a range of medical issues, but it has yet to be fully adapted for use in behavioral health. mHealth offers a number of advantages for serving older adults with behavioral health issues, particularly in the context of the extreme gaps in services available to this group. Given advances with design, mHealth interventions can be minimally intrusive and minimally visible-providing the older adult with privacy, independence, and intervention for issues for which they might not otherwise seek services due to embarrassment or shame. In addition to providing basic services, such as enhancing psychotropic medication adherence, it can also provide health providers with a way to assess and engage older adults in talking about a broad range of health issues, including mental health, substance use, and medication interactions in a non-stigmatizing, non-confrontational way. Older adults have already demonstrated a desire to interface with technology when addressing an issue that may be stigmatizing [86].

\section{Conclusion}

Despite continued myths to the contrary, older adults can and are often willing to engage with technology utilized for mHealth interventions. The major barrier for older adults to utilize mobile technology is the same barrier across the general population-cost. Barriers unique to older adults may be shared by those with a disability but only in some cases. Physical and cognitive changes that may result from aging should not be a permanent barrier to utilization of mobile technology - as design and proper training can address and facilitate easier engagement for individuals with these difficulties [117].

Two primary differences between older adults engaging in mHealth interventions, particularly for behavioral health enhancement, compared to younger adults is 1) the necessity that mHealth interventions should not replace social or face-to-face contact [92] and 2) the context in which older adults learn how to use technology. For younger users, mHealth interventions could be stand alone. For older users, it needs to be an ancillary or complimentary service-or one that is used to facilitate face-to-face contact with health care providers-so as not to increase social isolation, a key contributor to poor outcomes in older adults. For older adults, the learning environment needs to be particularly supportive.

Despite these differences, mobile technology and mHealth interventions offer a unique opportunity to address behavioral health at both the individual and population level. mHealth can provide excellent frontline assessment and intervention-facilitating participation of older adults in continuous health monitoring and ongoing contact with a health care provider.

\section{Declaration of interests}

These authors declare no conflict of interest.

\section{References}

1. U.S. Census Bureau (2012) Population profile of the United States. Retrieved from

2. Institute of Medicine (2012) The mental health and substance use workforce for older adults: In whose hands? Washington, DC: The National Academies Press.

3. Substance Abuse and Mental Health Services Administration (2014) Results from the 2013 National Survey on Drug Use and Health: Summary of National Findings, NSDUH Series H-48, HHS Publication No. (SMA) 14-4863. Retrieved from Rockville, MD

4. Institute of Medicine (2008) Retooling for an aging America: Building the health care workforce. Washington, DC: The National Academies Press.

5. Arvantes J (2010) Health care reform law will increase demand for preventive services, say experts AAFP News.

6. Families USA (2012) Medicare's preventive care benefit: What it means for you Retrieved from Washington, DC.

7. Richardson JE, Reid MC (2013) The promises and pitfalls of leveraging mobile health technology for pain care. Pain Med 14: 1621-1626. [Crossref]

8. Mercer K, Baskerville N, Burns CM, Chang F, Giangregorio L, et al. (2015) Using a collaborative research approach to develop an interdisciplinary research agenda for the study of mobile health interventions for older adults. JMIR Mhealth Uhealth 3: e11. [Crossref]

9. Mitzner TL, Boron JB, Fausset CB, Adams AE, Charness N, et al. (2010) Older adults talk technology: Technology usage and attitudes. Comput Human Behav 26: 17101721. [Crossref]

10. Morrow-Howell N, Proctor E, Choi S, Lawrence L, Brooks A, et al. (2008) Depression in public community long-term care: Implications for intervention development. $J$ Behav Health Serv Res 35: 37-51. [Crossref]

11. Bardram JE (2008) Pervasive healthcare as a scientific discipline. Methods Inf Med 47 178-185. [Crossref] 
12. Agyapong VI, Ahern S, McLoughlin DM, Farren CK (2012) Supportive text messaging for depression and comorbid alcohol use disorder: single-blind randomised trial. $J$ Affect Disord 141: 168-176. [Crossref]

13. Hall AK, Cole-Lewis H, Bernhardt JM (2015) Mobile text messaging for health: a systematic review of reviews. Annu Rev Public Health 36: 393-415. [Crossref]

14. Head KJ, Noar SM, Iannarino NT, Grant Harrington N (2013) Efficacy of text messaging-based interventions for health promotion: a meta-analysis. Soc Sci Med 97: 41-48. [Crossref]

15. Keoleian V, Polcin D, Galloway GP (2015) Text messaging for addiction: a review. $J$ Psychoactive Drugs 47: 158-176. [Crossref]

16. Muench F, Weiss RA, Kuerbis A, Morgenstern J (2013) Developing a theory driven text messaging intervention for addiction care with user driven content. Psychol Addict Behav 27: 315-321. [Crossref]

17. Quanbeck A, Chih MY2, Isham A1, Gustafson D1 (2014) Mobile Delivery of Treatment for Alcohol Use Disorders: A Review of the Literature. Alcohol Res 36: 111-122. [Crossref]

18. Nilsen W, Kumar S, Shar A, Varoquiers C, Wiley T, et al. (2012) Advancing the science of mHealth. J Health Commun 17 Suppl 1: 5-10. [Crossref]

19. Cole-Lewis H, Kershaw T (2010) Text messaging as a tool for behavior change in disease prevention and management. Epidemiol Rev 32: 56-69. [Crossref]

20. Flores Mateo G, Granado-Font E, Ferre-Grau C, Montana-Carreras X (2015) Mobile Phone Apps to Promote Weight Loss and Increase Physical Activity: A Systematic Review and Meta-Analysis. J Med Internet Res 17: e253. [Crossref]

21. Center for Technology and Aging (2011) mHealth Technologies: Applications to Benefit Older Adults (Draft). Retrieved from Oakland, CA:

22. Wright $P$ (2012) The internet's potential for enhancing healthcare. Gerontechnology 11: $35-44$.

23. Antypas K, Wangberg SC (2012) E-Rehabilitation - an Internet and mobile phone based tailored intervention to enhance self-management of Cardiovascular Disease: study protocol for a randomized controlled trial. BMC Cardiovasc Disord 12: 50. [Crossref]

24. Martín P, Sánchez M, Álvarez L, Alonso V, Bajo J (2011) Multi-agent system for detecting elderly people falls through mobile devices. In P. Novais, D. Preuveneers, \& J. M. Corchado (Eds.), Advances in Intelligent and Soft Computing 92: 93-99.

25. Foreman KF, Stockl KM, Le LB, Fisk E, Shah SM, et al. (2012) Impact of a text messaging pilot program on patient medication adherence. Clin Ther 34: 1084-1091. [Crossref]

26. Gaddam A, Mukhopadhyay SC, Gupta GS (2008) Development of a smart home for elder-people based on wireless sensors Lecture Notes in Electrical Engineering 20: 361-379.

27. Durick J, Robertson T, Brereton M, Vetere F, Nansen B (2013) Dispelling ageing myths in technology design. Paper presented at the Proceedings of the 25th Australian Computer-Human Interaction Conference: Augmentation, Application, Innovation, Collaboration OzCHI 2013.

28. Kowtko M (2012) Using assistive technologies to improve lives of older adults and people with disabilities. Paper presented at the 2012 IEEE Long Island Systems, Applications and Technology Conference, LISAT.

29. McCann RM, Keaton SA (2013) A cross cultural investigation of age stereotypes and communication perceptions of older and younger workers in the USA and Thailand. Educational Gerontology 39(5): 326-341.

30. McLeod E (2009) The use (and disuse) of mobile phones by baby boomers. Australian Journal of Emerging Technologies and Society 7: 28-38.

31. Niemelä-Nyrhinen J (2007) Baby boom consumers and technology: Shooting down stereotypes. Journal of Consumer Marketing 24: 305-312.

32. Olson KE, O'Brien MA, Rogers WA, Charness N (2011) Diffusion of Technology: Frequency of Use for Younger and Older Adults. Ageing Int 36: 123-145. [Crossref]

33. Hanson VL (2011) Technology skill and age: What will be the same 20 years from now? Universal Access in the Information Society 10: 443-452.

34. Barnard Y, Bradley MD, Hodgson F, Lloyd AD (2013) Learning to use new technologies by older adults: Perceived difficulties, experimentation behaviour and usability. Computers in Human Behavior 29: 1715-1724.

35. Kang H G, Mahoney DF, Hoenig H, Hirth VA, Bonato P, et al. (2010) In situ monitoring of health in older adults: Technologies and issues. $J$ Am Geriatr Soc 58: 1579-1586. [Crossref]
36. Damodaran L, Olphert CW, Sandhu J (2014) Falling off the bandwagon? Exploring the challenges to sustained digital engagement by older people. Gerontology 60: 163-173. [Crossref]

37. Arning K, Ziefle M (2007) Understanding age differences in PDA acceptance and performance. Computers in Human Behavior 23: 2904-2927.

38. File T (2013) Computer and internet use in the United States. Retrieved from Washington, DC: http://www.census.gov/prod/2013pubs/p20-569.pdf

39. Pew Research Center (2014) Older adults and technology. Retrieved from Washington, DC:

40. Choi NG (2011) Relationship between health service use and health information technology use among older adults: Analysis of the US National Health Interview Survey. J Med Internet Res 13: e33. [Crossref]

41. Hope A, Schwaba T, Piper AM (2014) Understanding digital and material socia communications for older adults. Paper presented at the Conference on Human Factors in Computing Systems - Proceedings.

42. LeRouge C, Van Slyke C, Seale D, Wright K (2014) Baby Boomers' adoption of consumer health technologies: Survey on readiness and barriers. J Med Internet Res 16. [Crossref]

43. Nahm ES, Bausell, B., Resnick, B., Covington, B., Brennan, P. F., Mathews, R., \& Park, J. H. (2011). Online research in older adults: Lessons learned from conducting an online randomized controlled trial. Appl Nurs Res 24: 269-275. [Crossref]

44. Pew Research Center (2015) The smartphone difference. Retrieved from Washington, DC:

45. Lam R, Lin VS, Senelick WS, Tran HT, Moore AA, et al. (2013) Older adult consumers' attitudes and preferences on electronic patient-physician messaging. Am J Manag Care 19: eSP7-eSP11. [Crossref]

46. Ruiz JG, Tunuguntla R, Cifuentes P, Andrade AD, Ouslander JG, et al. (2011) Development and pilot testing of a self-management internet-based program for older adults with overactive bladder. Urology 78: 48-53. [Crossref]

47. Dear BF, Zou J, Titov N, Lorian C, Johnston L, et al. (2013) Internet-delivered cognitive behavioural therapy for depression: a feasibility open trial for older adults. Aust $N Z J$ Psychiatry 47: 169-176. [Crossref]

48. Masukawa K, Rosenbloom D, Helmuth E, Liao D, Moore AA (2015) Older adults visit online sites for screening and brief intervention (SBI) for unhealthy alcohol use Paper presented at the Annual Scientific Meeting of the American Geriatrics Society, Washington, DC.

49. Kumar A, Lim H (2008) Age differences in mobile service perceptions: Comparison of Generation Y and baby boomers. Journal of Services Marketing 22: 568-577.

50. Salovaara A, Lehmuskallio A, Hedman L, Valkonen P, Nasanen J (2010) Information technologies and transitions in the lives of 55-65-year-olds: The case of colliding life interests. International Journal of Human-Computer Studies 68: 803-821.

51. Van Volkom M, Stapley JC, Malter J (2013) Use and perception of technology: Sex and generational differences in a community sample. Educational Gerontology 39: 729-740.

52. Chen K, Chan AH (2013) Use or non-use of gerontechnology--a qualitative study. Int $J$ Environ Res Public Health 10: 4645-4666. [Crossref]

53. Dickinson A, Hill RL (2007) Keeping in touch: Talking to older people about computers and communication. Educational Gerontology 33: 613-630.

54. McLeod E (2009) The use (and disuse) of mobile phones by baby boomers. Australian Journal of Emerging Technologies and Society 7: 28-38.

55. Morren M, van Dulmen S, Ouwerkerk J, Bensing J (2009) Compliance with momentary pain measurement using electronic diaries: a systematic review. Eur J Pain 13: 354365. [Crossref]

56. Kuerbis A, Muench F, Sacco P, Treloar H, Shao S, et al. (2015) Feasibility and exploratory analysis of ecological momentary assessment using mobile technology with middle aged and older adults. Paper presented at the Annual Scientific Meeting of the Research Society on Alcoholism, San Antonio, TX.

57. Smith A (2011) Americans and text messaging. Retrieved from Washington, DC: http://pewinternet.org/Reports/2011/Cell-Phone-Texting-2011/Main-Report/HowAmericans-Use-Text-Messaging.aspx

58. Hughes LD, Done J, Young A (2011) Not 2 old 2 TXT: There is potential to use email and SMS text message healthcare reminders for rheumatology patients up to 65 years old. Health Informatics J 17: 266-276. [Crossref] 
59. Park LG, Howie-Esquivel J, Chung ML, Dracup K (2014) A text messaging intervention to promote medication adherence for patients with coronary heart disease: A randomized controlled trial. Patient Education and Counseling 94: 261-268. [Crossref]

60. Muench F (2014) The Promises and Pitfalls of Digital Technology in Its Application to Alcohol Treatment. Alcohol Res 36: 131-142. [Crossref]

61. Dick JJ, Nundy S, Solomon MC, Bishop KN, Chin MH, et al. (2011) Feasibility and usability of a text message-based program for diabetes self-management in an urban African-American population. J Diabetes Sci Technol 5: 1246-1254. [Crossref]

62. Chatterjee S, Dutta K, Xie HQ, Byun J, Pottathil A, et al. (2013). Persuasive and pervasive sensing: A new frontier to monitor, track and assist older adults suffering from type- 2 diabetes. Paper presented at the Proceedings of the Annual Hawaii International Conference on System Sciences.

63. Müller AM, Khoo S, Morris T (2016) Text messaging for exercise promotion in older adults from an upper-middle-income country: Randomized controlled trial. $J$ Med Internet Res 18: e5. [Crossref]

64. Rau PLP, Hsu J (2005) Interaction Devices and Web Design for Novice Older Users. Educational Gerontology 31: 19-40.

65. Jayroe TJ, Wolfram D (2012) Internet searching, tablet technology and older adults. Proceedings of the American Society for Information Science and Technology 49: 1-3.

66. Neafsey PJ, Strickler Z, Shellman J, Chartier V (2002) An interactive technology approach to educate older adults about drug interactions arising from over-the-counter self-medication practices. Public Health Nurs 19: 255-262. [Crossref]

67. Lin CA, Neafsey PJ, Strickler Z (2009) Usability testing by older adults of a computermediated health communication program. J Health Commun 14: 102-118. [Crossref]

68. Romano Bergstrom J, Olmsted-Hawala E, Bergstrom H (2014) Older adults fail to see the periphery in a Web site task. Universal Access in the Information Society 1-10.

69. Brajnik G, Yesilada Y, Harper S (2011) Web accessibility guideline aggregation for older users and its validation. Universal Access in the Information Society 10: 403-423.

70. Kurniawan SH, King A, Evans DG, Blenkhorn PL (2006) Personalising web page presentation for older people. Interacting with Computers 18: 457-477.

71. Nicolau H, Guerreiro T, Jorge J, Gonçalves D (2014) Mobile touchscreen user interfaces: Bridging the gap between motor-impaired and able-bodied users. Universal Access in the Information Society 13: 303-313.

72. Pak R, Price MM, Thatcher J (2009) Age-sensitive design of online health information: Comparative usability study. J Med Internet Res 11: e45. [Crossref]

73. Chevalier A, Dommes A, Martins D (2013) The effects of ageing and website ergonomic quality on internet information searching. Ageing and Society 33: 1009-1035.

74. Juvina I, Taatgen NA (2009) A repetition-suppression account of between-trial effects in a modified Stroop paradigm. Acta Psychol (Amst) 131: 72-84. [Crossref]

75. Czaja SJ, Charness N, Fisk AD, Hertzog C, Nair SN, et al. (2006) Factors predicting the use of technology: Findings from the Center for Research and Education on Aging and Technology Enhancement (CREATE). Psychol Aging 21: 333-352. [Crossref]

76. Kowtko M (2012) Using assistive technologies to improve lives of older adults and people with disabilities. Paper presented at the 2012 IEEE Long Island Systems, Applications and Technology Conference, LISAT 2012.

77. Czaja SJ, Sharit J, Hernandez MA, Nair SN, Loewenstein D (2010) Variability among older adults in Internet health information-seeking performance.

78. Czaja SJ, Sharit J, Ownby R, Roth DL, Nair S (2001) Examining age differences in performance of a complex information search and retrieval task. Psychol Aging 16 564-579. [Crossref]

79. Choi NG, DiNitto DM (2013) Internet use among older adults: Association with health needs, psychological capital, and social capital. J Med Internet Res 15. [Crossref]

80. Elliot AJ, Mooney CJ, Douthit KZ, Lynch MF (2014) Predictors of older adults' technology use and its relationship to depressive symptoms and well-being. $J$ Geronto B Psychol Sci Soc Sci 69: 667-677. [Crossref]

81. Erbes CR, Stinson R, Kuhn E, Polusny M, Urban J, et al. (2014) Access, utilization, and interest in mHealth applications among veterans receiving outpatient care for PTSD. Mil Med 179: 1218-1222. [Crossref]

82. Zhou J, Rau PLP, Salvendy G (2014) Age-related difference in the use of mobile phones. Universal Access in the Information Society 13: 401-413.

83. Adams N, Stubbs D, Woods V (2005) Psychological barriers to Internet usage among older adults in the UK. Med Inform Internet Med 30: 3-17. []
84. Bjørneby S (1999) The Seniornett Project. ERCIM News 27.

85. Zwijsen SA, Niemeijer AR, Hertogh CMPM (2011) Ethics of using assistive technology in the care for community-dwelling elderly people: An overview of the literature. Aging Ment Health 15: 419-427. [Crossref]

86. Li J, Theng YL, Foo S, Fernando ONN (2013) Content analysis on user-focused support features of health support sites for geriatric depression. Paper presented at the Proceedings - 2013 IEEE International Conference on Healthcare Informatics.

87. Greenhalgh T, Wood GW, Bratan T, Stramer K, Hinder S (2008) Patients' attitudes to the summary care record and HealthSpace: Qualitative study. BMJ 336: 1290-1295.

88. Turner P, Turner S, Van de Walle G (2007) How older people account for their experiences with interactive technology. Behaviour \& Information Technology 26: 287-296.

89. Hernandez-Encuentra E, Pousada M, Gomez-Zuniga B (2009) ICT and older people: Beyond usability. Educational Gerontology 35: 226-245.

90. Wu YH, Damnée S, Kerhervé H, Ware C, Rigaud AS (2015) Bridging the digital divide in older adults: A study from an initiative to inform older adults about new technologies. Clin Interv Aging 10: 193-201. [Crossref]

91. Melenhorst AS, Rogers WA, Bouwhuis DG (2006) Older adults' motivated choice for technological innovation: Evidence for benefit driven selectivity. Psychol Aging 21: 190-195. [Crossref]

92. Bailey C, Sheehan C (2009) Technology, older persons' perspectives and the anthropological ethnographic lens. ALTER - European Journal of Disability Research / Revue Européenne de Recherche sur le Handicap 3: 96-109.

93. American Association of Retired Persons (AARP) (2008) Health @ home. Washington, DC: Author.

94. Selwyn N, Gorard S, Furlong J, Madden L (2003) Older adults' use of information and communications technology in everyday life. Ageing \& Society 23: 561-582.

95. Kurniawan SH (2008) Older people and mobile phones: A multi-method investigation. International Journal of Human-Computer Studies 66: 889-901.

96. Hardill I, Olphert CW (2012) Staying connected: Exploring mobile phone use amongst older adults in the UK. Geoforum 43: 1306-1312.

97. Center for Persons with Disabilities (2015) Writing clearly and simply. WebAIM http://webaim.org/techniques/writing/\#cog

98. Sharit J, Hernandez MA, Nair SN, Kuhn T, Czaja SJ (2011) Health problem solving by older persons using a complex government web site: Analysis and implications for web design. ACM Transactions on Accessible Computing 3.

99. Demiris G, Rantz M, Aud M, Marek K, Tyrer H, et al. (2004) Older adults' attitudes towards and perceptions of "smart home" technologies: a pilot study. Med Inform Internet Med 29: 87-94. [Crossref]

100. Cavender A, Bigham J (2011) Toward web accessibility for older users. Universal Access in the Information Society 10: 357-358.

101. Sayago S, Blat J (2011) An ethnographical study of the accessibility barriers in the everyday interactions of older people with the web. Universal Access in the Information Society 10(4): 359-371.

102. Rai A1, Chen L, Pye J, Baird A (2013) Understanding determinants of consumer mobile health usage intentions, assimilation, and channel preferences. J Med Internet Res 15: e149. [Crossref]

103. Haddad S, McGrenere J, Jacova C (2014) Interface design for older adults with varying cultural attitudes toward uncertainty. Paper presented at the Conference on Human Factors in Computing Systems - Proceedings.

104. Collerton D, Forster E, Packham D (2014) An exploratory study of the effectiveness of memory aids for older people living in supported accommodation. J Appl Gerontol 33: 963-981. [Crossref]

105. Broady T, Chan A, Caputi P (2010) Comparison of older and younger adults attitudes towards and abilities with computers: Implications for training and learning. British Journal of Educational Technology 41: 473-485.

106. Godfrey M, Johnson O (2009) Digital circles of support: Meeting the information needs of older people. Computers in Human Behavior 25: 633-642.

107. Czaja SJ, Sharit J, Lee CC, Nair SN, Hernández MA, et al. (2013) Factors influencing use of an e-health website in a community sample of older adults. $J$ Am Med Inform Assoc 20: 277-284. [Crossref] 
108. Kohlbacher F, Hang CC (2007, 2-4 Dec. 2007) Disruptive innovations and the greying market. Paper presented at the Industrial Engineering and Engineering Management, 2007 IEEE International Conference.

109. Muench F, Von Stolk-Cooke K, Kuerbis A, Stadler G, Baumel A, et al. (under review). A randomized controlled pilot trial of different mobile messaging interventions for problem drinking.

110. Arch A, Abou-Zahra S, Henry SL (2009) Older users online: WAI guidelines address older users web experience.

111. World Wide Web Consortium (2008) Web Content Accessibility Guidelines (WCAG) 2.0. Retrieved from WC3, http://www.w3.org/TR/WCAG20/: http://www. w3.org/TR/WCAG20/

112. Caldwell B, Cooper M, Reid LG, Vanderheiden G (2008) Web content accessibility guidelines (WCAG) 2.0.
113. Fisk AD, Rogers W, Charness N, Czaja SJ, Sharit J (2009) Designing for older adults: Principles and creative human factor approaches (2nd ed.). New York: CRC Press, Taylor and Francis Group.

114. Zaphiris P, Kurniawan S, Ghiawadwala M (2007) A systematic approach to the development of research-based web design guidelines for older people. Universal Access in the Information Society 6(1): 59-75.

115. Coughlin JF (2010) Understanding the janus face of technology and ageing: Implications for older consumers, business innovation and society. Australian Journal of Emerging Technologies and Society 8: 62-67.

116. Levine C (2004) Always on call: When illness turns families into caregivers (2nd ed.). New York, NY: United Hospital Fund.

117. Pew Research Center (2016) Mobile technology fact sheet. Retrieved from Pew Research Center: Internet, Science \& Tech website: doi:http://www.pewinternet.org/ fact-sheets/mobile-technology-fact-sheet/

Copyright: $\odot 2017$ Kuerbis A. This is an open-access article distributed under the terms of the Creative Commons Attribution License, which permits unrestricted use, distribution, and reproduction in any medium, provided the original author and source are credited. 